\title{
Condition of Cleanliness of Surfaces Close to Patients in an Intensive Care Unit
}

\author{
Adriano Menis Ferreira ${ }^{1}$ \\ Denise de Andrade $^{2}$ \\ Marcelo Alessandro Rigotti ${ }^{3}$ \\ Maria Verônica Ferrareze Ferreira ${ }^{4}$
}

\begin{abstract}
Surface cleaning is a well-known control procedure against the dissemination of microorganisms in the hospital environment. This prospective study, carried out in an intensive care unit over the course of 14 days, describes the cleaning/disinfection conditions of four surfaces near patients. In total, 100 assessments of the surfaces were carried out after they were cleaned. Three methods were used to evaluate cleanliness: a visual inspection, an adenosine triphosphate (ATP) bioluminescence assay and testing for the presence of Staphylococcus aureus and meticillin-resistant Staphylococcus aureus/MRSA. Respectively, $20 \%, 80 \%$ and $16 \%$ of the assessments by the visual method, ATP and the presence of Staphylococcus aureus/MRSA failed. There were statistically significant differences $(p<0.05)$ between the rates of failure of the cleaning using the ATP method, compared to the visual and microbiological methods. The visual inspection was not a reliable measure to evaluate surface cleanliness. The results demonstrated that the adopted cleaning routine should be reconsidered.
\end{abstract}

Descriptors: Staphylococcus aureus; Equipment Contamination; Cross Infection; Methicillin Resistance; Housekeeping, Hospital.

\footnotetext{
${ }^{1}$ RN, Post doctor in Nursing. Adjunct Professor, Universidade Federal de Mato Grosso do Sul, MS, Brazil. E-mail: a.amr@ig.com.

${ }^{2}$ RN, Free Lecture. Associate Professor, Escola de Enfermagem de Ribeirão Preto, Universidade de São Paulo, WHO Collaborating Centre for Nursing Research Development, SP, Brazil. E-mail: dandrade@eerp.usp.br.

${ }^{3}$ RN, Masters's Student in Nursing, Escola de Enfermagem de Ribeirão Preto, Universidade de São Paulo, WHO Collaborating Centre for Nursing Research Development, SP, Brazil. E-mail: marcelosaude@hotmail.com.

${ }^{4}$ RN, Doctoral Student in Nursing, Escola de Enfermagem de Ribeirão Preto, Universidade de São Paulo, WHO Collaborating Centre for Nursing Research Development, SP, Brazil. E-mail: mveronica@eerp.usp.br.
}

Corresponding Author: Adriano Menis Ferreira Universidade Federal de Mato Grosso do Sul. Departamento de Enfermagem Av. Ranulpho Marques Leal, 3220 Distrito Industrial CEP: 79610-100 Três Lagoas, MS, Brasil E-mail: a.amr@ig.com.br 


\section{Condições de limpeza de superfícies próximas ao paciente, em uma unidade de terapia intensiva}

A limpeza das superfícies é reconhecidamente medida de controle da disseminação de microrganismos no ambiente hospitalar. Este estudo prospectivo, realizado em uma unidade de terapia intensiva, durante 14 dias, teve como objetivo descrever as condições de limpeza/desinfecção de quatro superfícies próximas do paciente. Cem avaliações das superfícies foram realizadas após o processo de limpeza. Utilizaram-se três métodos para avaliar a limpeza: inspeção visual, adenosina trifosfato (ATP) bioluminescência e presença de Staphylococcus aureus/MSRA. Respectivamente, 20, 80 e 16\% das avaliações pelos métodos visual, ATP e presença de Staphylococcus aureus/MSRA foram consideradas reprovadas. Houve diferenças estatisticamente significantes $(p<0,05)$ entre as taxas de reprovação da limpeza utilizando os métodos ATP, comparado ao visual e microbiológico. A inspeção visual não se mostrou medida confiável para avaliar a limpeza das superfícies.

Os resultados demonstram que a rotina de limpeza adotada precisa ser revista.

Descritores: Staphylococcus aureus; Contaminação de Equipamentos; Infecção Hospitalar; Resistência a Meticilina; Serviço Hospitalar de Limpeza.

\section{Condiciones de limpieza de superficies próximas al paciente en una unidad de terapia intensiva}

La limpieza de las superficies es reconocidamente una medida de control de la diseminación de microorganismos en el ambiente hospitalario. Este estudio prospectivo, realizado en una unidad de terapia intensiva, durante 14 días, tuvo como objetivo describir las condiciones de limpieza/desinfección de cuatro superficies próximas al paciente. Cien evaluaciones de las superficies fueron realizadas después del proceso de limpieza. Se utilizaron tres métodos para evaluar la limpieza: inspección visual, adenosín trifosfato (ATP) bioluminiscencia y presencia de Staphylococcus aureus/MSRA. Respectivamente, $20 \%, 80 \%$ y $16 \%$ de las evaluaciones por los métodos: visual, ATP y presencia de Staphylococcus aureus/MSRA, fueron consideradas reprobadas. Hubo diferencias estadísticamente significativas $(p<0.05)$ entre las tasas de reprobación de la limpieza utilizando los métodos ATP, comparado al visual y al microbiológico. La inspección visual no se mostró una medida confiable para evaluar la limpieza de las superficies. Los resultados demostraron que la actual rutina de limpieza precisa ser modificada.

Descriptores: Staphylococcus aureus; Contaminación de Equipos; Infección Hospitalaria; Resistencia a la Meticilina; Servicio de Limpieza en Hospital.

\section{Introduction}

Although the role of the healthcare environment in the spread of some infections is far from universally agreed upon, circumstantial evidence suggests that contaminated hospital environmental surfaces can be a risk factor for infection caused by some pathogens.
In addition, there has been increased recognition that environmental measures should form a crucial component of the overall strategy for preventing healthcare-associated infections ${ }^{(1-7)}$. 
Cleaning consists of the removal of dirt or contaminants found on surfaces using mechanical (friction), physical (temperature) or chemical (sanitizing) means, during a given period of time. The cleaning of a patient's hospitalization unit should be done on a daily basis, or whenever needed, being done before and not at the same time as floor cleaning. The cleaning of horizontal surfaces which have contact with patient's and team's hands deserve more attention, such as door handles, telephones, light switches, bed rails, nurse call buttons and others ${ }^{(8)}$.

Cleaning has never been regarded as an evidencebased science and consequently receives little attention from the scientific community ${ }^{(9)}$. Since there are no scientific standards to measure the effect of an individual cleaner, or assess environmental cleanliness, finding the evidence to benefit the control of infection is further hampered ${ }^{(10)}$. Cleaning is routinely monitored by visual audits. While looking to see if a ward is 'clean' may aesthetically satisfy, it does not provide a reliable assessment of the infection risk for an individual patient in that ward(11). The organisms that cause infection are invisible to the naked eye and their existence is not necessarily associated with any visible signs ${ }^{(10)}$

Sites that are frequently touched by hands are thought to present the greatest risk for patients, for instance, those surfaces situated right beside a patient ${ }^{(12-14)}$. The responsibility for cleaning near-patient sites commonly and frequently touched by hands does not always rest with the ward cleaners, however, since beds, drip stands, lockers and over-the-bed tables are more commonly cleaned by nurses ${ }^{(13-14)}$. Nurses are also responsible for the decontamination of more delicate clinical equipment. This overlapping of cleaning responsibilities has created some confusion; it has also meant that cleaning opportunities for some items are missed or abandoned(15).

Methods for monitoring the effectiveness of cleaning procedures include the visual assessment of surfaces, application of fluorescent dye to surfaces with subsequent assessment of residual dye after cleaning, determination of aerobic colony counts, an indicator organism and detection of adenosine triphosphate (ATP) on surfaces. Few investigators have evaluated ATP bioluminescence methods for monitoring cleanliness in hospitals ${ }^{(9,11,16-17)}$.

This study describes the conditions of cleanliness of surfaces using three different methods after routine daily cleaning.

\section{Methods}

A prospective study was carried out over a period of two weeks in January 2010 in a medical and general surgery Intensive Care Unit (ICU) in a Philanthropic Hospital. The study ICU has 10 beds for patients over 18 years of age. There was a $100 \%$ occupation level throughout the duration of the study.

The four environmental surfaces (bed rails, crank, bedside table, buttons of infusion pump) were selected for culturing after routine cleaning without notifying the cleaning staff (responsible for cleaning the ceilings, walls and floors) or staff nurses (nursing technicians and auxiliaries) in order to minimize changes in their behaviors. These objects were chosen because they are frequently touched, potentially exposing medical staff and patients ${ }^{(18)}$

According to the formally established routine, a staff nurse cleans the patient unit, including the furniture and equipment around the patient, with a cotton cloth soaked in $70 \%$ alcohol (w/v). The same cloth is used to clean at least two patient units, given that each nursing auxiliary/technician is responsible for two patients, which is noteworthy. Each cotton cloth is changed only when a staff nurse recognizes it is visibly dirty, with the exception of isolation rooms in the ICU.

During each monitoring period, samples were collected within 10 minutes of the completion of the morning cleaning session, every day, for 14 days. This allows a description of the condition of cleanliness for the surfaces rather than contamination after cleaning.

The materials at testing sites were mostly stainless steel or laminate plastic covering for wood. For each site, the general surface condition, the presence of moisture, and visual cleanliness were noted. The visual assessments were done by one person using standardized descriptors. The presence of adenosine triphosphate (ATP), which is derived from organic soil and microorganisms, at each site was assessed by a rapid hygiene test of ATP bioluminescence, using the Biotrace Cleantrace system (3M Clean-Trace ATP System; 3M) ${ }^{(17)}$. We targeted $S$ aureus, including Meticillin-resistant Staphylococcus aureus (MRSA), as an indicator organism (10-11).

The results were analyzed according to various test standards selected for this study, which specify: (i) a visual 'pass' was based on a surface being graded as 'clean' based on the absence of visual soiling, moisture, staining or poor surface conditions; (ii) an ATP 'pass' was a bioluminescence result $<500$ relative light units 
(RLU) and (iii) an Staphylococcus aureus/MRSA 'pass' results from the absence of any detection of MRSA on a surface ${ }^{(10-11,18-19)}$.

Petri Film ${ }^{T M}\left(3 M^{T M}\right.$, St Paul, MN, USA) Staph Express $3 \mathrm{M}^{\mathrm{TM}}$ plates prepared with modified BairdParker chromatogenic medium, Staphylococcus aureus selective and differential, were used for the collection of microorganisms. The plates were pressed onto the surface for 1 minute. At the end of each collection, plates were identified with: date, time and place of collection. They were then stored in polystyrene boxes and transported to the Microbiology Laboratory.

A sampling area of $30 \mathrm{~cm}^{2}$ and incubation at $35^{\circ} \mathrm{C}$ for 24-48h was adopted for the Petrifilm ${ }^{\mathrm{TM}}$ model. Readings of Petrifilm ${ }^{\mathrm{TM}}$ plates were done using a stereomicroscope (Nikon, JP) under reflected light and were quantitatively evaluated through CFU (Colony Forming Units). Redviolet colonies were considered to be Staphylococcus aureus.

Methicillin susceptibility was tested by the oxacillin resistance screening test. Petri plates containing MullerHinton agar, with 4\% Sodium Chloride and $6 \mu \mathrm{g} /$ $\mathrm{ml}$ oxacillin added, known as MRSA medium (Probac do Brasil $\left.^{\circledR}\right)$, were used. These microorganisms were transplanted into Brain Heart Infusion (BHI) broth and incubated at $37^{\circ} \mathrm{C}$ for 24 hours. After this period, they were inoculated onto plates and incubated at $37^{\circ} \mathrm{C}$ for 24 and 48 hours. Any growth on the plate was considered to be MRSA.

The data collected from all of the samples were input into the Statistical Package for the Social Sciences, version 15.0 (SPSS), for statistical analysis. The RLU values for four frequently touched surfaces were compared using the Kruskal-Wallis 1-way analysis-ofvariance test. Differences in proportion were compared by means of the $\chi^{2}$ test. In all cases significance was set at least at $\mathrm{p}<0.05$.

\section{Results}

Four surfaces were selected for environmental surface cleanliness testing, using three different methods. In total, 100 visual assessments, 100 ATP measurements, and 100 Staphylococcus aureus determinants were recorded.

The majority of surfaces were dry and visually free from dirt, dust, stains and smears. Twenty surfaces, 10 bedside tables, 8 bed rails and 2 cranks failed due to sticky deposits.

Failure rates for surface cleanliness, using the different methods, varied considerably (Table 1 ).
Differences in ATP, visual and microbiological failure rates (Table 2$)$ were significant $(p<0.05)$ and consistent, and varied from $14 \%$ to $18 \%$. The differences between visual and microbiological failure rates were not significantly different. The differences between ATP and Staphylococcus aureus/MRSA failure rates were not significant and varied from $12 \%$ to $18 \%$.

Table 1 - Failure rates (\%) after cleaning using different assessment methods for surfaces near patients in Intensive Care Unit

\begin{tabular}{lccc}
\hline \multicolumn{1}{c}{ Examined Surfaces } & Visual & ATP & S. aureus/MRSA \\
\hline Bed rails $(n=25)$ & 8 & 22 & 7 \\
Bedside table $(n=25)$ & 10 & 24 & 9 \\
Bed crank $(n=25)$ & 2 & 20 & 6 \\
Infusion pump button $(n=25)$ & 0 & 15 & 4 \\
Total $(n=100)$ & 20 & 81 & 26 \\
\hline
\end{tabular}

ATP, Adenosine Triphosphate.

MRSA = Meticillin-resistant Staphylococcus aureus.

Table 2 - Differences in failure rates after cleaning, between visual and two other assessment methods for surfaces near patients in Intensive Care Unit

\begin{tabular}{lcc}
\hline \multicolumn{1}{c}{ Examined Surfaces } & ATP (\%) & S. aureus/MRSA (\%) \\
\hline Bed rails & 14 & 1 \\
Bedside table & 14 & 1 \\
Bed crank & 18 & 4 \\
Infusion pump button & 15 & 4 \\
Total & 60 & 10 \\
\hline
\end{tabular}

ATP, Adenosine Triphosphate.

MRSA $=$ Meticillin-resistant Staphylococcus aureus.

Failure rates provide an indication of cleaning efficacy in relation to benchmark values but do not provide an indication of the extent of failure. A summary of the overall ATP data to illustrate mean, median values and the range of data points is provided in Table 3 . Wide variations in counts, using ATP, were found between sites. The ATP results, after cleaning, varied from 34 RLUs to 7201.

Table 3 - Adenosine Triphosphate (ATP) readings of samples obtained from 4 frequently touched surfaces near patients in intensive care unit after daily cleaning

\begin{tabular}{lccc}
\hline \multicolumn{1}{c}{ Surface sample } & $\begin{array}{c}\text { Mean } \\
\text { (RLU) }\end{array}$ & $\begin{array}{c}\text { Median } \\
\text { (RLU) }\end{array}$ & $\begin{array}{c}\text { Range } \\
\text { (RLU) }\end{array}$ \\
\hline Bed rails $(n=25)$ & 983 & 160 & $72-7201$ \\
Bedside table $(n=25)$ & 830 & 398 & $102-2341$ \\
Bed crank $(n=25)$ & 388 & 121 & $54-4654$ \\
Infusion pump button $(n=25)$ & 509 & 354 & $34-3672$ \\
\hline
\end{tabular}

RLU, relative light units. 
It can be seen that there is no relationship between ATP failures and microbiological failures. It can be seen, too, that there is relationship between microbiological failures and visual failures $(p<0.05)$. However, only one indicator microorganism was used, which may have influenced this result.

In the present study, $80 \%$ of surfaces in the ward were considered visually clean after cleaning. Using visual assessment, most sites would have been considered acceptably clean, but when benchmark ATP values were applied, only $19 \%$ were considered clean after cleaning.

After routine cleaning, $S$. aureus was most frequently isolated from bedside tables (six times), bed rails (four times), and bed cranks and infusion pump buttons both had positive results three times. Although only a low number of samples were available at each site, there were no apparent differences in isolation frequencies between the surfaces. Only six were identified as meticillin resistant.

\section{Discussion}

The aim of cleaning should be to keep surfaces visibly clean, to disinfect commonly touched surfaces more frequently than surfaces not commonly touched, and to clean up spills promptly(1-3). Thus, near patient (e.g. chart tables, bed frames) and frequently touched (bed crank, bed rail, Infusion pump button) environmental surfaces may become contaminated with epidemiologically important microbes and should be cleaned regularly, as well as at patient discharge as per hospital policy.

Although the recommendation of a Brazilian regulatory body ${ }^{(8)}$ is to first clean the target surface with soap and detergent, during the accomplishment of this study, cloths soaked in alcohol, applied directly to the surfaces, was observed. This can undermine the process of disinfection.

The results indicate that visual assessment, on its own, was an unreliable indicator of surface cleanliness and as a means for assessing the effectiveness of cleaning protocols. The visual assessment method used in this study, as shown by others, proved the least sensitive method for assessing cleanliness. The disparity is especially clear when compared with such rapid hygiene-testing methods as ATP bioluminescence ${ }^{(19-23)}$.

Visual assessment of cleanliness in isolation can be overestimated. Instead, an integrated approach to monitoring cleanliness is recommended. Previous studies have identified poor standards of cleanliness in hospitals, often with normal cleaning resulting in no improvement (i.e. reduction) in ATP or microbiological levels ${ }^{(11,16-17,19)}$.

An early study(11) specifically examined concurrent visual assessment of hospital environments against chemical (bioluminescence detection) and microbiological methods of measuring organic and microbial soil. While $82 \%$ of wards seemed visibly clean (after cleaning), only $30 \%$ were microbiologically clean, and only $25 \%$ were free from organic soil. Another study(19) has evaluated the effectiveness and thoroughness of routine cleaning activities in hospitals. It compared 2 standardized, observation-based audit guidelines with a risk-based audit tool used in conjunction with rapid environmental testing via an ATP bioluminescence tool for several observation periods in 4 hospitals. Although $90 \%$ of the sites tested appeared visually clean immediately after routine disinfection/cleaning activities, none of the sites were found to be effectively sanitized using the ATP bioluminescence monitor, and only $10 \%$ met bacteriologic food-handling standards. In comparison, another study(23) showed that $93.3 \%$ of areas were visibly clean, $92 \%$ were microbiologically clean and $71.5 \%$ were free from organic soil.

The present study did not show a correlation between ATP and Staphylococcus aureus/MRSA values, a finding replicated by others ${ }^{(23)}$. However, as the two techniques measure different parameters, an integrated approach to monitoring cleaning regimens may be the most useful. Indicator organisms such as MRSA indicate contamination and do relate to a potential risk of infection. It has been shown that $1-27 \%$ of general ward surfaces harbor MRSA(1).

Microbiological testing may or may not correlate with ATP readings, since the two techniques measure different parameters. Microbiological methods detect residual micro-organisms (usually bacteria), which should decrease as a result of cleaning. The magnitude of any decrease will depend on the method, materials and chemicals used. ATP bioluminescence is a measure of cleanliness that detects organic soiling (microbial and non-microbial ATP) ${ }^{(18)}$.

Staphylococci were found on surfaces after the existing cleaning regimen, of which $16 \%$ were presumptive S. aureus/MRSA. Other studies on this topic have reported contamination rates in isolation rooms, such as $27.0 \%$, $^{(24)}$ and $50 \%{ }^{(22)}$.

MRSA is an important agent of hospital-acquired infections (HAIs) in ICUs. A rigid implementation of 
protocols to prevent HAIs, isolation precautions and hand hygiene is recommended in order to control it(25). Numerous studies illustrate that many different inanimate surfaces in hospitals can become a reservoir for MRSA ${ }^{(1-}$ 23). Several studies specifically address environmental MRSA contamination within isolation units ${ }^{(4-7,11-12,18-23)}$. However, the various studies of MRSA detection on surfaces in isolation rooms are generally not comparable, since the patient characteristics, the microbiological screening methods, the sampling regimen, as well as the manner, frequency, and effectiveness of cleaning and disinfection methods vary considerably.

Environmental contamination may contribute to the transmission of healthcare pathogens when healthcare workers contaminate their hands or gloves by touching contaminated surfaces, or when patients come into direct contact with contaminated surfaces $^{(24)}$.

Contaminated environmental surfaces that are commonly touched by patients and/or staff may act as sources for hand transfer. In support of this, a study of 12 nurses $^{(12)}$ demonstrated that five (42\%) of the 12 contaminated their gloves with MRSA while performing activities that required no direct patient contact but involved touching objects in the rooms of MRSA patients. In another study, $31 \%$ of volunteers who touched bed rails and over-the-bed tables in patient rooms contaminated their hands with S. aureus (35\% of which were an MRSA strain) ${ }^{(12)}$. When volunteers touched bed rails and over-the-bed tables in unoccupied rooms that had been given a final cleaning, as opposed to a daily one, $7 \%$ contaminated their hands with $S$. aureus ${ }^{(13)}$.

The role of contaminated environmental surfaces in the transmission of healthcare-associated pathogens is also supported by the fact that cleaning and/or disinfection of the environment can reduce the incidence of healthcare-associated colonization or infection. However, evidence for the effect of basic cleaning on reducing the acquisition rate of MRSA in hospitals is scant. Studies have demonstrated that an intervention consisting of increased cleaning, Environmental Services staff education, use of a black-light monitoring system and the use of ATP Bioluminescence improved cleaning and decreased the likelihood of positive cultures for either MRSA ${ }^{(16-17,23)}$.

The ATP and microbiological results after cleaning varied greatly; this has been previously reported(11) and generally indicates inconsistencies in the quality of cleaning.

The present results indicate considerable levels of invisible organic soiling remaining on surfaces after cleaning. In the present study it is possible that irregularly or infrequently changing cleaning materials was a source of contamination. Results obtained with routine cleaning may in part relate to the use of reusable cleaning materials rather than disposable ones, which were not changed at adequate intervals in the existing routine protocol, and are known to spread contamination $^{(26)}$. It is likely that a number of the failure rates in ATP/microbiological counts after cleaning were as a result of dirt and/or microorganisms being redistributed rather than removed by cleaning. Simple changes to the cleaning processes used in hospitals can achieve substantial improvements leading to a reduction in the residual surface levels of ATP, indicator organisms, and methicillin-resistant Staphylococcus aureus(22).

If cleaning is intended to remove pathogens from a surface, it is necessary that cleaning be able to reduce residual organic material to a low level. Thus, a cleaning protocol that fails to achieve benchmark values for the removal of organic soil, as determined by a sensitive ATP test, is unlikely to be fit for that purpose. In a hospital environment, this would necessitate either reassessment of staff adherence to the protocol, or the adoption of new cleaning methods or frequencies. Microbiological assessment in specific instances, and a more general use of sensitive ATP testing in training and process management, may be one way of formulating an integrated and cost effective cleaning assessment strategy ${ }^{(21)}$.

This study has limitations. A convenience sample of only four objects does not represent the ICU as a whole and there may be items that could have been positive for MRSA but were not sampled. Samples before cleaning were not measured, which only allows describing the cleanliness conditions of surfaces close to patients. Financial constraints limited the amount of samples taken.

Further investigations of the clinical significance of hospital environmental contamination and of more effective cleaning methods are required.

\section{Conclusion}

Visual assessment alone did not always provide a meaningful measure of surface cleanliness or cleaning efficacy and should be used only as the first stage in an integrated monitoring program.

In the hospital used for this study, the variability in results during routine environmental monitoring suggested that the cleaning routine should be 
reconsidered. A well designed cleaning schedule should specify monitoring and the corrective action to be taken if, after cleaning, the site is still not cleaned satisfactorily. In the present study, the cleaning program required neither monitoring nor corrective action. Simple changes to the cleaning processes used in hospitals can achieve substantial improvements leading to a reduction in the residual surface levels of ATP, indicator organisms, and methicillin-resistant Staphylococcus aureus.

\section{References}

1. Boyce JM. Environmental contamination makes an important contribution to hospital infection. J Hosp Infect. 2007;65(Suppl. 2):50-4.

2. Dettenkofer $M$, Spencer RC. Importance of environmental contamination e a critical view. J Hosp Infect. 2007;65(Suppl. 2):55-7.

3. Fraise AP. Decontamination of the environment. J Hosp Infect. 2007;65(Suppl. 2):58-9.

4. Hardy KJ, Oppenheim BA, Gossain S, Gao F, Hawkey PM, A study of the relationship between environmental contamination with meticillin-resistant Staphylococcus aureus (MRSA) and patients' acquisition of MRSA. Infect Control Hosp Epidemiol. 2006;27:127-32.

5. Sexton T, Clarke P, O'Neill E, Dillane T, Humphreys $\mathrm{H}$. Environmental reservoirs of meticillin-resistant Staphylococcus aureus in isolation rooms: correlation with patient isolates and implications for hospital hygiene. J Hosp Infect. 2006;62:187-94.

6. Lemmes SW, Hafner H, Zolldann D, Stanzel S, Lutticken R. Distribution of multi-resistant gram-negative versus gram-positive bacteria in the hospital inanimate environment. J Hosp Infect. 2004;56:191-7.

7. Al-Hamad A, Maxwell S. How clean is clean? Proposed methods for hospital cleaning assessment. J Hosp Infect. 2008; 70:328-34.

8. Agência Nacional de Vigilância Sanitária Segurança do paciente em serviços de saúde: limpeza e desinfecção de superfícies. Agência Nacional de Vigilância Sanitária. Brasília: Anvisa; 2010. 116 p.

9. Dancer SJ. The role of environmental cleaning in the control of hospital-acquired infection. J Hosp Infect. 2009;73:378-85.

10. Dancer SJ. How do we assess hospital cleaning? A proposal for microbiological standards for surface hygiene in hospitals. J Hosp Infect. 2004;56:10-5.

11. Griffith CJ, Cooper RA, Gilmore J, Davies C, Lewis M. An evaluation of hospital cleaning regimes and standards. J Hosp Infect. 2000;45:19-28.
12. Bhalla A, Pultz NJ, Gries DM, Ray AJ, Eckstein EC, Aron DC, et al. Acquisition of nosocomial pathogens on hands after contact with environmental surfaces near hospitalized patients. Infect Control Hosp Epidemiol. 2004;25:164-7.

13. Dancer SJ. Importance of the environment in meticillin-resistant Staphylococcus aureus acquisition: the case for hospital cleaning. Lancet Infect Dis. 2008;8:101-13.

14. White L, Dancer SJ, Robertson C, McDonald J. Are hygiene standards useful in assessing infection risk? Am J Infect Control. 2008;36:381-4.

15. Blythe D, Keenlyside D, Dawson SJ, Galloway A. Environmental contamination due to methicillinresistant Staphylococcus aureus (MRSA). J Hosp Infect. 1998;38:67-70.

16. Carling PC, Briggs JL, Perkins J, Highlander D Improved cleaning of patient rooms using a new targeting method. Clin Infect Dis. 2006;42:385-8.

17. Boyce JM, Havill NL, Dumigan DG, Golebiewski M, Balogun O, Rizvani R. Monitoring the effectiveness of hospital cleaning practices by use of an adenosine triphosphate bioluminescence assay. Infect Control Hosp Epidemiol. 2009;30:678-84.

18. Griffith CJ, Obee P, Cooper RA, Burton NF, Lewis M. The effectiveness of existing and modified cleaning regimens in a Welsh hospital. J Hosp Infect. 2007;66:352-9.

19. Malik R, Cooer R, Griffith C. Use of audit tools to evaluate the efficacy of cleaning systems in hospitals. Am J Infect Control. 2003;31:181-7.

20. Larson EL, Aiello AE, Gomez-Duarte C, Lin SX, Lee $\mathrm{L}$, Della-Latta $\mathrm{P}$, et al. Bioluminescence ATP monitoring as a surrogate marker for microbial load on hands and surfaces in the home. Food Microbiol. 2003;20:735-9.

21. Lewis T, Griffith C, Gallo M, Weinbren M. A modified ATP benchmark for evaluating the cleaning of some hospital environmental surfaces. J Hosp Infect. 2008;69:156-63.

22. Lewis T, Gallo M, Weinbren M, Griffith CJ. An assessment of the effectiveness of modified hospital cleaning protocols using visual, ATP bioluminescence, and microbiological analysis. J Hosp Infect. 2006;64(Suppl. 1):55-6.

23. Sherlock O, O'Connell N, Creamer E, H Humphreys. Is it really clean? An evaluation of the efficacy of four methods for determining hospital cleanliness. J Hosp Infect. 2009;72: 140-6. 
24. Boyce JM, Potter-Bynoe G, Chenevert C, King T. Environmental contamination due to meticillinresistant Staphylococcus aureus: possible infection control implications. Infect Control Hosp Epidemiol. 1997; 18:622-7.

25. Fortaleza CR, Melo EC de, Fortaleza CMCB. Nasopharyngeal colonization with methicillin-resistant staphylococcus aureus and mortality among patients in an intensive care unit. Rev. Latino-Am. Enfermagem. [periódico na Internet]. out 2009 [acesso $15 \mathrm{fev}$ 2010]; 17(5): 677-82. Disponível em: http://www. scielo.br/scielo.php?script=sci_arttext\&pid=S01041692009000500013\&lng=pt. doi: 10.1590/S010411692009000500013.

26. Moore G, Griffith CJ. A laboratory evaluation of the decontamination properties of microfiber cloths. J Hosp Infect. 2006;64:379-85. 